\title{
A Educação Física no Ensino Médio no "Currículo da Cidade de São Paulo": uma leitura crítica
}

Physical Education in High School in the "Curriculum of the City of São Paulo": a critical reading

La Educación Física en la Escuela Secundaria en el "Plan de Estudios de la Ciudad de São Paulo": una lectura crítica

L'Education Physique au Lycée dans le "Curriculum de la Ville de São Paulo”: une lecture critique

Graduado em Educação Física pelas Faculdades Integradas de Guarulhos, Guarulhos, SP, Brasil, Mestre em Educação pela Pontifícia Universidade de São Paulo, São Paulo, Brasil, e doutor em Ciências Sociais pela Universidade Estadual Paulista "Júlio de Mesquita Filho", Araraquara, SP, Brasil. Atualmente é professor da Universidade Cruzeiro do Sul, São Paulo, SP, Brasil. 
Resumo

Abstract

Resumen
$\mathrm{O}$ artigo trata de uma leitura crítica do currículo da rede pública municipal para o Ensino Médio, produzido a partir da Base Nacional Comum Curricular, a ser finalizado no ano de 2020. O documento curricular apresenta um caráter progressista, mostrou-se de fácil manuseio para consulta das professoras e dos professores da rede municipal da cidade de São Paulo. Do ponto de vista dos processos formativos, parece haver uma grande demanda também por discussões de caráter filosófico, para que a proposta possa ser plenamente compreendida e implementada pelo conjunto docente. O documento traz uma fundamentação teórica marcadamente crítica em relação à sociedade contemporânea. Sua estrutura assemelha-se à da Base Nacional Curricular, trazendo a Educação Física dentro do campo de Linguagens e suas tecnologias.

Palavras-Chave: Currículo; Formação de Professores; Ensino Médio; Práticas Pedagógicas; Visão Crítica da Sociedade.

El artículo trata de una lectura crítica del plan de estudios de la red pública municipal para la escuela secundaria, elaborado a partir de la base del plan de estudios nacional común, que se finalizará en el año 2020. El documento del plan de estudios es de carácter progresivo y ha demostrado ser fácil de utilizar para su consulta por los profesores de la red municipal de la ciudad de São Paulo. Desde el punto de vista de los procesos formativos, parece haber una gran demanda también de discusiones filosóficas, para que la propuesta pueda ser plenamente comprendida y aplicada por la comunidad docente. El documento aporta una base teórica marcadamente crítica en relación con la sociedad contemporánea. Su estructura se asemeja a la de la Base Curricular Nacional, llevando la Educación Física dentro del campo de los Idiomas y sus tecnologías.

Keywords: Curriculum; Teacher Education; High School; Pedagogical Practices; Critical View of Society.

El artículo trata de una lectura crítica del plan de estudios de la red pública municipal para la escuela secundaria, elaborado a partir de la base del plan de estudios nacional común, que se finalizará en el año 2020. El documento del plan de estudios es de carácter progresivo y ha demostrado ser fácil de utilizar para su consulta por los profesores de la red municipal de la ciudad de São Paulo. Desde el punto de vista de los procesos formativos, parece haber una gran demanda también de discusiones filosóficas, para que la propuesta pueda ser plenamente comprendida y aplicada por la comunidad docente. El documento aporta una base teórica marcadamente crítica en relación con la sociedad contemporánea. Su estructura se asemeja a la de la Base Curricular Nacional, llevando la Educación Física dentro del campo de los Idiomas y sus tecnologías.

Palabras Clave: Plan de Estudios; Formación de Profesores; Escuela Secundaria; Prácticas Pedagógicas; Visión Crítica de la Sociedad. 
Resumé

L'article traite d'une lecture critique du programme du réseau public municipal pour le lycée, produit à partir de la Base commune des programmes nationaux, qui sera finalisé en 2020. Le document du programme scolaire est de nature progressive et s'est avéré facile à utiliser pour la consultation par les enseignants du réseau municipal de la ville de São Paulo. Du point de vue des processus de formation, il semble y avoir une grande demande de discussions philosophiques, afin que la proposition puisse être pleinement comprise et mise en œuvre par la communauté des enseignants. Le document apporte une base théorique nettement critique par rapport à la société contemporaine. Sa structure ressemble à celle de la base curriculaire nationale, en faisant entrer l'éducation physique dans le domaine des langues et de ses technologies.

Mots Clés: Autoritarisme; Question Sociale; Démocratie; Révolution Bourgeoise; Modernisation Conservatrice. 


\section{Para Começo de Conversa}

A leitura não depende da organização do tempo social, ela é, como o amor, uma maneira de ser.

A questão não é de saber se tenho tempo para ler ou não (tempo, que, aliás, ninguém de dará), mas se me ofereço ou não à felicidade de ser leitor.

(Daniel Pennac; 1996, p. 119).

O desenvolvimento desta reflexão segue as orientações recomendadas por um roteiro de análise encaminhado pela equipe da Secretaria Municipal da Educação, responsável pela produção do currículo da cidade, em sua versão para o ensino médio.

Gostaria de iniciar minhas considerações parabenizando o grupo de professoras e professores que construíram os documentos a partir de muitas mãos. Sabe-se que essa não é uma tarefa simples e fácil, ao contrário, é complexa e tensa. Estão em jogo sempre diferentes visões de mundo, inclusive dentro de um mesmo campo político, como no chamado campo progressista, e amplia-se, evidentemente, quando temos nesse universo sujeitos que se colocam como representantes de diferentes campos políticos.

O trabalho se transformou num documento curricular interessante, progressista, que traz uma marca política e ética que avança em relação à Base Nacional Comum Curricular (BNCC), já que aponta inequivocamente para uma perspectiva crítica da sociedade, buscando a superação das diferentes formas de injustiça social (Alves, 2013; Silva, 2012). Não que aponte para fórmulas mágicas para isso, mas traz reflexões e sugere estratégias, como exemplos, que colaboram na formação de professoras e professores a caminho de novas experimentações que poderão resultar em novas pedagogias para uma educação comprometida com uma sociabilidade mais solidária, mais justa.

Farei meus apontamentos quanto aos documentos curriculares para o ensino médio a partir de uma reflexão política, ética e pedagógica. Diante das condições sociais cada vez mais precarizadas entre a população trabalhadora e pobre, que vive nos bairros periféricos da cidade de São Paulo, é necessário se olhar para o currículo e para as práticas pedagógicas a partir dessas condições sociais.

Essa análise se baseará em duas importantes contribuições: a noção de "Saberes imprescindíveis" trazido por Miguel Arroyo (2012), que questiona o quanto um currículo escolar consegue de fato atender às necessidades e ansiedades e aos interesses das crianças e jovens que têm uma vida precarizada. Como saberes imprescindíveis sugiro: o direito que os jovens têm de saber sobre as forças que atuam para que suas vidas sejam como são, e como essas forças, em certa medida, os impedem de atingir um desenvolvimento pleno. Do meu ponto de vista, é importante que se perceba como os saberes descritos como objetivos de aprendizagem dialogam ou não com o que considero como saberes imprescindíveis.

A outra noção que servirá como base para os apontamentos é a de "Educabilidade", apoiado em Néstor Lópes (2008). Neste caso, trata-se de um conjunto de capacidades, de disposições que os estudantes devem ter para que possam avançar em seus estudos, para que possam ter uma experiência duradoura e de sucesso na escola. Ao mesmo tempo, o conceito de educabilidade aponta para a necessidade de o sistema educacional, as escolas, os professores, desvelem o grau de educabilidade que seus educandos e educandas trazem para a prática educativa, para que possam construir 
coletivamente as bases necessárias para o progresso do educando, a partir de sua própria realidade, de suas próprias condições (Silva \& Ansara, 2014).

\section{Indo aos Documentos}

O conceito orientador, "educação integral", fala em equidade, em fortalecer políticas que levem a ela. Apresenta o desejo de garantir as condições necessárias para se assegurar os direitos de aprendizagem a todas as crianças, independentemente de sua condição socioeconômica, cultural, étnico-racial, geográfica, entre outras. Essa ideia expressa a necessidade de incorporação de práticas escolares e pedagógicas que busquem garantir a permanência de todas as crianças na escola por longo tempo; o acolhimento aos diferentes segmentos sociais, com amorosidade, com respeito, com entendimento da situação complexa de todos os jovens, é de fundamental importância para garantir a permanência dos jovens na escola.

Mas esse não é um movimento curricular simples, é preciso investir na formação de base teórica no campo das ciências humanas e sociais, para que todas as professoras e professores - uma vez que nem todos tiveram oportunidade para uma formação filosófica mais aprofundada -, possam vir a compreender a dinâmica social que produz diuturnamente a desigualdade; e, assim, reconhecerem que a desigualdade não é da natureza; que a meritocracia é apenas uma falácia, já que é impossível para um determinado sistema social avaliar o mérito real de qualquer pessoa, pois não capta o ponto de partida e nem o caminho mais ou menos espinhoso de cada trajetória, e muito menos classificar as pessoas a partir desse elemento presente em todas as pessoas: o mérito.

A citação do professor Boaventura de Souza Santos que o documento traz em sua fundamentação é emblemática para uma nova política, para uma nova ética e para uma nova pedagogia: "[...] temos o direito a ser iguais quando a nossa diferença nos inferioriza; e temos o direito a ser diferentes quando a nossa igualdade nos descaracteriza. Daí a necessidade de uma igualdade que reconheça as diferenças e de uma diferença que não produza, alimente ou reproduza as desigualdades". (sem a referência bibliográfica no documento, há apenas a citação).

Embora o documento traga um fundamento ético e político, apontando para a necessidade de se dar voz e reconhecimento aos grupos oprimidos, como os diferentes grupos de jovens das famílias dos trabalhadores, às mulheres, à população negra, ao grupo de pessoas que não se enquadram no padrão heteronormativo, entre outros, sabe-se que uma parte considerável dos docentes não se afina, ao menos inteiramente, com essa perspectiva; e há ainda uma outra parcela do professorado que não teve uma formação filosófica suficiente para alcançar de forma crítica esse debate.

Infelizmente a formação inicial sempre foi insuficiente no que diz respeito uma formação humana mais complexa, mais aprofundada, que permitisse um debate sobre o mundo em que vivemos e as forças políticas que o faz estar como está. A chamada formação técnica de professores prosperou livremente por décadas; após o período de redemocratização teve de enfrentar currículos para a formação de professores com novos enfoques sobre a educação e o mundo que passaram a colocar a questão da função social da escola como questão fundamental. Entretanto, diante da correlação de forças que experimentamos neste novo momento no Brasil, com a hegemonia de um projeto 
neoliberal, do ponto de vista econômico, e conservador nas questões de comportamento, torna-se cada vez maior o risco de um empobrecimento da formação teórica, ética e política dos professores, com efeitos mais danosos especialmente nos cursos das universidades privadas.

Assim, a formação continuada, permanente, é que pode garantir que se promova grandes mudanças na educação de jovens da cidade de São Paulo, numa perspectiva crítica, problematizadora, sensível e emancipadora.

No caso específico da rede municipal de ensino da cidade de São Paulo, o processo de formação continuada, especialmente por meio da Jornada Especial Integral de Formação (JEIF), presente na carreira dos docentes deste município, mas apenas entre aqueles que atingem 25 aulas semanais atribuídas, é bem consistente, são 4 encontros semanais de aproximadamente 1,5 horas cada, mas há também outras possibilidades de formação, há aquelas protagonizadas pelas 13 Diretorias Regionais de Ensino (DREs), que reúnem um percentual de professores-formadores em suas formações, que têm por responsabilidade levarem para as formações nas escolas o que foi discutido; e até pela Secretaria Municipal de Educação (SME), quando reúne uma pequena parcela de interessados em determinadas temáticas.

Será de extrema importância o comprometimento dos docentes nessa proposta curricular, para que haja acolhimento pessoal e curricular aos diferentes grupos sociais, com suas diferentes características; para que esses jovens de vidas precarizadas avancem em direção ao direito ao desenvolvimento pleno.

Há a necessidade de formação no campo das teorizações filosóficas inspiradoras, de caráter crítico ao status quo, seja no amplo campo do marxismo, do neomarxismo, da escola de Frankfurt, ou de outros campos epistemológico como o pós-estruturalismo, os estudos culturais, a fenomenologia, entre outras teorizações que possam contribuir com o desvelamento das relações de poder que constituem a realidade social, para que todos as educadoras e educadores possam ampliar suas possibilidades de leitura de mundo e, consequentemente, de posicionamento ético e de atuação pedagógica.

Essa formação é necessária, mas trabalhosa, porque uma parte considerável do professorado criará diferentes formas de resistência, e é por meio das reuniões de JEIF e no desenvolvimento de projetos inter e/ou transdisciplinar que essas questões poderão ganhar forma e apontar para novas possibilidades de trabalho pedagógico.

A citação abaixo, excerto do documento curricular, estabelece a relação entre as Ciências Humanas e Sociais, o que para o campo da Educação Física representa um grande avanço e, ao mesmo tempo, uma grande fonte de resistência, especialmente para os docentes que possuem uma história vinculada ao esporte ou à especificidade da aprendizagem motora. Afinal, este é um debate que está longe de se encerrar.

Isto implica a ampliação de conhecimentos sobre como as Ciências Humanas e Sociais estudam as práticas corporais; a formação ética e responsável para que os jovens possam fazer escolhas conscientes sobre sua participação nas práticas corporais ao longo da vida, em diversas situações de interação social (São Paulo, 2020b:18).

O currículo está organizado em três partes: áreas de conhecimento; os componentes curriculares; e percursos de estudos e formação. É importante que essas partes dialoguem entre si, que em cada escola se caminhe para ações pedagógicas interdisciplinares ou ainda transdisciplinares. Para que isso seja possível é preciso que haja formação para que os docentes possam se comprometer com um projeto complexo como esse. 
A organização em áreas de conhecimento abre possibilidades para novas reflexões e ações de interdisciplinaridade ou transdisciplinaridade que poderão gerar projetos ou ações didáticas que ampliarão os olhares das professoras e professores sobre os saberes que poderão desenvolver. Ao sair de sua confortável área de saber, professoras e professores, poderão vislumbrar novos caminhos para a docência e para os educandos.

Quanto aos objetos de conhecimento e os objetivos de aprendizagem, deve-se destacar que estejam vinculados em alguma medida aos saberes imprescindíveis. Indagações de como tratar certos saberes que tangenciam outros saberes mais complexos, mais imprescindíveis, deve alimentar as reflexões e práticas pedagógicas.

Os objetos e os objetivos estão alinhados à BNCC, mas apresentam uma maior coerência por demonstrar uma relação estreita entre os fundamentos teóricos do documento e seus objetivos.

A concepção de juventude, apresentada nos documentos, aponta para as possibilidades de protagonismo, articulando os projetos de vida com a dimensão comunitária, coletiva e participativa. E a expectativa que o documento apresenta sobre os jovens é de heterogeneidade, é de jovens trabalhadores e pobres. Mas será sempre importante reconhecer de onde vêm esses jovens e quais os requisitos materiais e imateriais que a escola espera deles, e o que a escola e as professoras e professores podem fazer para ajustar as linhas entre a comunidade e a escola, ou seja, ajustar o grau necessário de educabilidade. Em outras palavras, como construir com esses alunos concretos um certo grau de educabilidade que os tornem capazes de se manterem na escola e com sucesso.

A noção de currículo posta no documento está alicerçada na discussão contemporânea de currículo, e se coloca como fator determinante para se pensar práticas pedagógicas que dialoguem com os desafios a serem enfrentados nos dias de hoje. Ele se propõe plural, orientador, não linear; visto como processos permanentes e não um produto acabado, e vê os professores como protagonistas do currículo e colocando os estudantes no centro dessa matriz.

O acesso e a permanência na escola fazem parte dos projetos estratégicos no Programa de Metas. No entanto, não há nenhuma estratégia explícita no documento, e nenhuma recomendação mais criteriosa sobre esse componente da política educacional, que é da maior importância para os jovens dos bairros periféricos e pobres da cidade.

A permanência na escola por longos períodos está ligada a uma aproximação das disposições, das capacidades, do entendimento que o jovem tem do mundo, da compreensão da linguagem utilizada pelos colegas e docentes, da capacidade de dialogar, com a expectativa que os sistemas escolares, a escola, as professoras e professores têm desse background que os diferentes educandos trazem.

Assim, a permanência do estudante na escola por um longo período, e com sucesso - o que significa dizer que: não abandone a escola antes de se formar e que se desenvolva neste período -, é um objetivo decisivo; e isso implica no trabalho da escola em ajustar essas linhas. Esse não é um trabalho pedagógico fácil, precisará da mediação de uma coordenação pedagógica capaz de mobilizar o grupo e de um esforço coletivo do grupo docente para a construção de critérios para esse ajuste.

Segundo o documento, "Percursos de Estudo e Formação" deverão, sempre que possível, estabelecer conexões com as seguintes temáticas: ética, cidadania, democracia, relações étnico-raciais, direitos humanos, diversidade, juventudes, tecnologias e cultura digital, relações interpessoais, meio ambiente e sustentabilidade, inclusão de pessoas com deficiência e transtornos globais do desenvolvimento, gênero e sexualidade, mundo do trabalho, saúde e bem-estar, saúde pública, projeto de vida, entre outras temáticas emergentes. Essa determinação é de suma importância para construir os critérios de educabilidade e, consequentemente, para as práticas pedagógicas, desde que se traga as diferentes vozes para o debate, estimulando todos os alunos a se manifestarem, a se expressarem e 
tendo sempre suas vozes legitimadas (Silva, 2007; Barboza e Cols., 2017; Batista e cols., 2019; Vaz, 2019).

Todos os eixos estabelecidos podem dialogar com uma educação libertária: investigação Científica; mediação e intervenção sociocultural; empreendedorismo; multiculturalismo e multiletramentos; processos criativos; gestão de conteúdos e informações; mediação e intervenção em política econômica. Entretanto, esses eixos, por si só, não suficientes para construírem possibilidades democráticas de educabilidade, esses eixos só se tornarão efetivos se olhados a partir de uma concepção crítica da realidade, e que considere a leitura de mundo e o ponto de vista dos próprios educandos (Freire, 1986, 1997; Santos, 2020).

$\mathrm{O}$ documento traz uma linguagem plenamente compreensível às educadoras e educadores. Embora eu tenha sentido falta de citações ao longo do texto. As citações são importantes porque elas determinam melhor o diálogo, passa-se a saber com quem se está falando. Todavia, sem essa delimitação, ela também pode servir como um alargador dos conceitos, ampliando as fronteiras, fazendo com que um número maior de pessoas se sinta representado; e como este é um documento construídos a muitas mãos, penso que isso ajuda no processo de compreensão e comprometimento por parte de um número maior de professoras e professores.

Alguns termos podem apresentar compreensão equivocada, ou parcial, por parte dos leitores. Todos os termos empregados em um texto são polissêmicos, por isso a importância de explicitá-los. Por exemplo, o termo cidadania pode ter vários entendimentos; pode-se ter uma compreensão em que o apenas o voto seja suficiente para caracterizar o exercício político do indivíduo, ou pode-se entender que a cidadania exige uma participação ativa na sociedade, manifestando-se legitimamente em todos as esferas sociais, inclusive na pressão ou resistência aos poderes instituídos por meio de coletivos sociais. Ao se deixar que o próprio leitor lhe dê o sentido que lhe for mais próximo, perde-se a oportunidade de clareza dos objetivos e da intencionalidade do projeto

Na historização do componente curricular se diz corretamente que a Educação Física:

Historicamente, a primeira vez em que se agrupou as disciplinas de línguas (nacional e estrangeiras), de Arte e de Educação Física em uma Área, inicialmente denominada 'Linguagens, Códigos e suas Tecnologias' foi nos Parâmetros Curriculares Nacionais para o Ensino Médio (PCNEM), lançados em 2000. Posteriormente, a Área passou a ser denominada como Linguagens ou Linguagens e suas Tecnologias (São Paulo, 2020b:1).

Penso ser honesto reconhecer que em 1992, na primeira edição da publicação de "Metodologia de Ensino da Educação Física", já aparecia de forma clara a questão da linguagem. Penso ser importante esse resgate, para que os professores possam ter a ideia de que essa discussão tem pelo menos 30 anos, eis a citação:

A educação física é uma disciplina que trata, pedagogicamente na escola do conhecimento de uma área denominada aqui de cultura corporal. Ela será configurada com temas ou formas de atividades, particularmente corporais, como as nomeadas anteriormente: jogo, esporte, ginástica, dança ou outras, que constituíram seu conteúdo. $O$ estudo desse conhecimento visa apreender a expressão corporal como linguagem. (Soares e cols. 1992:61-62). (Grifo nosso).

Mesmo se considerando que as discussões teóricas sobre o corpo como linguagem, ou o corpo como texto, estejam muito à frente do que foi posto no início dos anos de 1990, é relevante esse destaque, porque marca uma passagem significativa para a área, que já se fazia presente desde meados da década de 1980. 
Do ponto de vista conceitual, as categorias que estão presentes no documento fazem parte de um grande arcabouço teórico com um olhar crítico sobre a realidade. Com a falta de citações, fica mais restrito observar o alinhamento teórico, mas certamente há um alinhamento político das categorias empregadas.

A questão da ciência na construção de mentalidades de mulheres e homens com apreço pelos saberes e produção científicos, não apenas como apreciadores das descobertas, mas como sujeitos da produção científica, é necessário cada vez mais, especialmente em tempos como os que temos vivido. A citação abaixo é um bom exemplo do que o documento traz.

"As práticas do campo de estudo e pesquisa ampliam o repertório cultural e ajudam a desenvolver e estruturar o pensamento científico, crítico, a criatividade, a comunicação e a resolução de problemas." (São Paulo, 2020b:10). O excerto abaixo, extraído do documento curricular, traz uma boa reflexão sobre linguagem e metalinguagem, mediando para ações metodológicas da prática pedagógica.

Mais que isso, trata-se de prover experiências de aprendizagem através das quais os alunos desenvolvem estratégias para "ler" o novo e o pouco familiar (designs), seja qual for a forma em que eles se manifestem. Ao invés de simplesmente falar sobre designs autoritários, trata-se de se questionar a razão dos designs ou sobre a relação entre a forma e a função da significação. Além disso, os alunos deverão ser capazes de esboçar, por meio de várias metalinguagens, as formas que assumem os significados contemporâneos e, por meio desses construtos, seus próprios enquadramentos de explicações funcionais (Cope \& Kalantzis, 2009 citado por São Paulo, 2020b:11).

O currículo apresenta possibilidades para a prática pedagógica, traz referenciais para se pensar os fundamentos éticos e políticos dessas práticas. Os objetivos descritos estão alinhados com a perspectiva teórica em que o documento está ancorado. O documento está alinhado com Base Nacional Comum Curricular (BNCC), embora, do ponto de vista da fundamentação teórica e da coerência entre esta e as propostas pedagógicas, organizadas por objetos de conhecimento e objetivos de desenvolvimento e aprendizagem, esteja à frente, apresentando uma direção claramente progressista.

Há na BCNN algumas competências específicas de Linguagens e suas tecnologias, acompanhadas do que chamam no documento de "habilidades" que penso que poderiam ter tido uma melhor apropriação pelo documento específico de Educação Física, embora o documento já dialogue com esses apontamentos. Essas competências, que também podem ser vistas como objetivos, podem ter um papel facilitador para o desenvolvimento de projetos interdisciplinares ou transdisciplinares, como a própria criação das diferentes áreas apontam.

O texto, de um modo geral, apresenta-se de forma coerente com uma perspectiva crítica de sociedade, reconhece as características da população pobre dos bairros periféricos da cidade de São Paulo e propõe a escuta, a atenção a esses jovens, para que possam ter uma efetiva participação no processo de desenvolvimento social.

Para facilitar a visualização do conjunto das aprendizagens propostas, os quadros contendo objetos de conhecimento e objetivos de aprendizagem foram organizados por eixo da cultura corporal nos anos do Ensino Médio, na expectativa de que os estudantes possam se apropriar, seja por vivências seja por reflexões, do maior número possível de objetos e de experiências. O diálogo com os jovens, com a sua realidade e a cultura local irão ser determinantes na variedade de oportunidades de experiências, na profundidade do aprendizado dentro de um determinado objeto. Trazendo plasticidade à proposta como sinal de respeito a esta diversidade. (São Paulo, 2020b:23-24).

Esse conjunto montado numa forma de quadro pode contribuir visualmente às consultas que professoras e professores poderão fazer com uma certa regularidade ao documento. Já foi destacado anteriormente que o 
documento curricular não pretende ser um currículo prescrito; neste caso, fica garantida a possibilidade de os docentes irem além, ultrapassarem a lista de objetos e objetivos de desenvolvimento e aprendizagem. O excerto abaixo, retirado do documento curricular, ilustra o que se espera que a escola desenvolva com seus alunos. Mas é importante destacar que a escola precisa construir um grau de educabilidade que possibilite esse importante passo no desenvolvimento da escolaridade prolongada e de sucesso para todos os jovens.

mas apoia o jovem a mobilizar e integrar tais conhecimentos, para ampliar suas possibilidades de análise e abstração da própria experiência, a fim de fazer escolhas conscientes, informadas e eticamente comprometidas com os valores democráticos e os Direitos Humanos. Nessa perspectiva, espera-se que o estudante possa refletir sobre questões como: Qual sua postura como praticante e/ou torcedor de esportes? Seus gestos, movimentos e palavras propagam discursos machistas, misóginos, homofóbicos e racistas? Como esse jovem faz escolhas relativas à prática de ginásticas? Busca padrões de beleza e, muitas vezes, consome sem consciência suplementos, drogas, produtos? Ou percebe o sentido de adotar práticas de ginástica para cuidar de si integralmente? Em sua relação com práticas corporais reproduz a gordofobia? Ou compreende a prática da ginástica como modo de expressar a própria corporeidade, respeitando diferentes padrões corporais? (São Paulo, 2020b:18).

O documento fala em estratégias de ensino que chame a participação e tomada de decisões por meio de processos democráticos. Esse é um elemento de primeira grandeza num currículo voltado para a população precarizada das periferias; mas é preciso entendê-los, é preciso que os docentes desenvolvam a capacidade de se colocar no lugar do Outro a partir do quadro de vida do Outro, e não do seu próprio. Ou seja, é preciso reconhecer a história viva desses jovens a partir dos seus relatos e do conhecimento da realidade social tão perversa que os transformam em corpos precarizados.

O currículo diz que os "estudantes nas aulas de Educação Física precisam ter momentos de aprendizagem que acolham suas necessidades, interesses e desejos" (São Paulo, 2020b: 19). Por que isso caberia apenas às aulas de educação física? Tal alerta pode dar a impressão de que as aulas de educação física estão realmente à mercê dos interesses imediatos dos estudantes, enquanto outras, talvez as "mais importantes", não possam se dar a esse empreendimento.

O excerto abaixo, retirado do documento curricular, é um grande desafio, e é preciso que a formação profissional, política e ética de professoras e professores lhe permita esse trânsito entre as utopias e as possibilidades trazidas pelas novas gerações. O docente precisa se reinventar, enquanto tal, todos os dias, em cada aula, para que possa de fato estabelecer um diálogo profícuo, necessariamente com respeito, com esses jovens.

"Como geração mais nova, cabe aos jovens reinventar o mundo e nós, professores, precisamos nos perguntar como formamos os jovens para serem diferentes de nós e, ao mesmo tempo, como mantemos nossa responsabilidade de promover o acesso aos conhecimentos historicamente construídos." (São Paulo, 2020b:20). O excerto abaixo, também retirado do documento, fala em pacto e repactuar. Penso que é preciso ampliar esse termo, a ideia de pacto não permite lidar com liberdade criativa, crítica, visto que de antemão se estabelecem limites para se reinventar. Tende a tolher as manifestações ou produzir ações de resistência que possam ser entendidas pelos docentes como indisciplina ou qualquer coisa que se assemelhe à criação de um ambiente fora do controle. Assim, pensar num ambiente aberto e respeitoso, pode produzir espaços mais democráticos e desafiadores tanto aos estudantes quanto aos professores. 
"Suas culturas transgridem, constroem visões de mundo próprias, ao mesmo tempo já cristalizaram modos próprios de vivenciar o papel de alunos das aulas de Educação Física, que muitas vezes precisarão ser repactuados no Ensino Médio." (São Paulo, 2020b: 20).

No que diz respeito à organização curricular é importante ressaltar que não se trata de uma camisa de força, de um currículo prescrito, mas ao contrário, o que se pretende é que ele possa ser inspirador. Os próprios eixos de conteúdos, que estão exatamente como na Base Nacional Comum Curricular, podem ser questionados, eles não devem ser entendidos como grupos de saberes previamente fechados. O excerto abaixo aponta o diálogo com a realidade de cada escola, com o diagnóstico e o planejamento de cada professor e seus alunos.

Para organizar as aprendizagens ao longo de três anos do Ensino Médio, o Currículo da Cidade propõe objetos de conhecimento e objetivos de aprendizagem e desenvolvimento nos diferentes eixos de conteúdo da cultura corporal: jogos e brincadeiras, esportes, danças, ginásticas, lutas e práticas corporais de aventura, diferenciando focos de trabalho em cada ano do Ensino Médio. É importante destacar que esta proposta de organização deve respeitar o diálogo com a realidade de cada escola, com o diagnóstico e o planejamento de cada professor com seus estudantes, o que torna possível a sua flexibilização, modificação ou até proposta de ampliação de objetos e objetivos previstos. Ou seja, este não é um quadro estanque ou uma proposta rígida, mas sim um quadro organizador susceptível de autoria docente em cada escola, em articulação com o Projeto Pedagógico e em diálogo com os estudantes e a comunidade. (São Paulo, 2020b: 22).

O documento traz uma interessante e atual discussão acerca dos princípios metodológicos e plenamente alinhado com os fundamentos teóricos apresentados tanto no documento introdutório quanto no documento específico.

O excerto abaixo apresenta um excelente exemplo, e ainda desmistifica a ideia equivocada de que a práxis deve ser apresentada em sala de aula, numa aula expositiva. Ao contrário, trata-se do reconhecimento dela como processo de conhecimento, em que todo sujeito que se movimenta carrega nele o seu fazer cultural, ideológico e social.

Para explicitar mais claramente a proposta lançamos mão com conceito de práxis cunhado por Paulo Freire. Para o autor a práxis supõe relações dialéticas e interdependentes entre teoria e prática, portanto a práxis é atividade prática fundamentada teórica e eticamente. O conceito de práxis contribui para o entendimento da complexidade de aprendizagens em jogo nas aulas de Educação Física. Nessa concepção, não é possível praticar a linguagem corporal sem pensar sobre ela. O sujeito que Se-movimenta carrega em seu fazer os sentidos culturais, ideológicos, sociais de seu fazer, e é justamente para trazer à tona, analisar, refletir e ampliar tais sentidos que as práticas precisam vir acompanhadas de momentos de pesquisa, análise e reflexão. Mas não se trata de um conhecimento exposto pelo professor em uma aula teórica ou da mera análise científica e cultural das práticas, mas de processo de construção de conhecimentos e posicionamentos éticos que nascem da experiência refletida, da práxis constante de alunos e professores. A práxis supõe a tomada de consciência e reflexão acerca das experiências corporais e de seus sentidos culturais. Não existe, portanto, prática sem significação teórica, conceitual, estando a práxis comprometida com a leitura de mundo dos jovens do Ensino Médio. (São Paulo, 2020b: 25)

A proposta dialoga diretamente com as professoras e professores. Apresenta possibilidades de ação pedagógica, que poderá auxiliar os docentes na reflexão metodológica, oferece ideias e 
referências para aprofundamento dos estudos por parte dos educadores. Os próximos três excertos ilustram bem o que afirmamos, pode ser um pouco longo, mas vale a pena retomá-lo:

Para que professores e estudantes promovam os objetivos de aprendizagem e desenvolvimento propostos do Currículo, serão necessárias aulas em diferentes ambientes da escola e fora dela, com a mobilização de diferentes recursos das linguagens, diferentes habilidades e competências, que permeiam a atuação dos estudantes nos diferentes campos da atividade humana que integram as práticas pedagógicas presentes na área de Linguagens e suas Tecnologias (São Paulo, 2020b: 27-28). [Grifo nosso].

Traduzir o que as danças representam para os jovens exigirá não só o próprio entendimento do estudante sobre a dança, mas conhecer diferentes possibilidades de apropriação desse objeto do conhecimento, compreender os significados dados pelas diferentes culturas juvenis, analisar a relação com as músicas, gostos e interesses variados, entre outras ações. Até a de desconstruir suas relações criadas com a dança até o momento para atingir um patamar de conhecimento mais amplo, aprofundado e conectado à ecologia dos saberes da dança (São Paulo, 2020b: 28). [Grifo nosso].

"Para isso, não basta ler, pesquisar, interpretar, discutir, mas também sentir, sensibilizar-se, experimentar, apreciar e traduzir interculturalmente, sem perder de vista a si mesmo, outros pontos de vista, outras questões, argumentos, sentidos e gestos atribuídos às práticas corporais”. (São Paulo, 2020b: 28).

A questão metodológica tem uma importância fundamental numa proposta como essa. No excerto a seguir vemos uma síntese dos elementos metodológicos propostos no documento curricular: a pesquisa, a participação democrática, contextualização cultural, a articulação dos saberes, a práxis e a pluralidade e diversidade. Todos esses elementos juntos estiveram ausentes na formação de professores de Educação Física por décadas. Apenas a partir dos anos de 1990 é que começaram a povoar, ainda lentamente, os cursos de Licenciatura em Educação Física.

O movimento que traz essas questões para os currículos de formação inicial não foi suficiente para tornar esse modelo curricular na formação inicial em hegemônico. Assim, temos de reconhecer que a formação que as professoras e professores da rede municipal tiveram em serviço, ao longo da carreira, foi responsável por uma formação mais crítica de sociedade e de educação. Desta forma, é fundamental que questões de base para a formação dos professores circulem pelos espaços de formação, como JEIF, ou mesmo encontros nas DREs.

Essa abordagem metodológica está ancorada na compreensão de que, ao produzir atos de linguagens no âmbito das práticas corporais, os jovens transformam, refazem a experiência cultural, expressam suas identidades, produzem novos significados, os quais podem ser garantidos pelo uso de metodologias que envolvam a participação democrática, a pesquisa como fundamento da educação, a contextualização cultural, a articulação dos saberes, a reflexão-ação-reflexão e a pluralidade e diversidade (São Paulo, 2020b: 29-30). 
A inclusão de parte dos Objetivos de Desenvolvimento Sustentável (ODS) ${ }^{1}$ nos quadros que apresentam os objetos de conhecimento e os objetivos de desenvolvimento e aprendizagem, que deverão ser constantemente consultados por professores e coordenação, é uma forma de dar visibilidade às questões que afetam o planeta e as condições de vida da maioria da população. Mesmo que não haja estratégias explícitas no documento, o fato de estar visível, de certo modo, leva professoras, professores e coordenação pedagógica a revisitarem o texto, os objetivos, e incluírem, assim, em suas pautas de formação perguntas como: o que podemos fazer? O que temos feito? E, assim, quem sabe, cada coletivo poderá produzir novas pedagogias, novas possibilidades.

No Ensino Médio, a Área de Linguagens e suas Tecnologias tem a responsabilidade de propiciar oportunidades para a consolidação e aprofundamento das diversas habilidades das linguagens, através da interação em campos de atuação diversos, vinculados com o enriquecimento cultural próprio, o trabalho, a continuação dos estudos e as práticas cidadãs conscientes e críticas, visando às metas de Desenvolvimento Sustentável (ODS) da Agenda 2030, buscando colaborar para: a proteção dos recursos naturais e do clima do planeta para as gerações futuras; a erradicação da pobreza e da fome e a garantia de dignidade, igualdade e de vidas prósperas e plenas em harmonia com a natureza; a promoção de uma sociedade pacífica, justa e inclusiva e de uma agenda de parcerias em prol dessas metas (São Paulo, 2020b: 4).

\section{Enfim...}

O documento apresentado se caracteriza por avanços importantes na concepção curricular e dos conceitos que o povoa. Entretanto, é importante destacarmos que o documento pode ser apenas um documento, caso não haja condições e vontade política de colocá-lo em prática.

Do ponto de vista dos saberes imprescindíveis, o documento apresenta um olhar marcado para as necessidades dos alunos, para o reconhecimento do contexto em que vivem esses jovens; assim, caberá a cada professora e professor encontrar o seu caminho pedagógico para esse empreendimento, e, talvez, quem sabe, compartilhar suas ações com os colegas. Já quanto a questão da educabilidade, o documento não apresentou uma preocupação explícita de se identificar o estágio em que os jovens chegam, para que a partir daí, se desenvolva o programa curricular; embora, indiretamente, ao levantar a questão do contexto em que vivem os jovens, pode ser um indicativo para uma ação pedagógica mais adequada.

Como assinalado ao longo do texto, as intenções do documento são extremamente dependentes das condições políticas. É preciso que haja vontade política da Secretaria da Educação para o

${ }^{1}$ Publicadas por chefes de Estado e de Governo e altos representantes, reunidos na sede das Nações Unidas em Nova York de 25 a 27 de setembro de 2015. Adotou-se uma decisão histórica sobre um conjunto de objetivos e metas universais e transformadoras que é abrangente, de longo alcance e centrado nas pessoas. 
investimento nas formações permanentes, e com qualidade, com atenção ao desenvolvimento processual. As DREs precisam assumir seu papel na defesa e na direção de uma escola democrática. A direção da escola precisará estar plenamente imbuída na construção de um ambiente favorável para o trabalho coletivo, e a coordenação pedagógica na construção dos processos formativos que se dão na escola. E, finalmente, os professores e professoras, que serão os agentes desse processo educativo, terão de se abrir ao entendimento de uma nova proposta curricular, abraçarem o posicionamento ético, político e pedagógico, e transcenderem o documento, fazerem de sua história, como pessoa e como profissional, a história dos jovens pobres da periferia de São Paulo.

Seria interessante que pudéssemos ver o resultado dessa proposta curricular daqui a alguns anos. Afinal, avaliar um documento é muito diferente de analisar os resultados que o documento produz. Penso que seria válido, tanto do ponto de vista político como científico, que se desenvolvessem estudos que pudessem apontar os avanços reais e as resistências ocorridas ao longo dos anos.

Assim, concluo meu parecer parabenizando mais uma vez a todas as pessoas envolvidas nesse gigantesco processo de construção curricular por meio de consultas à base docente e olhando sempre para um mundo mais justo, mais democrático, mais aberto, mais solidário.

Mãos à obra. 


\section{Referências Bibliográficas}

Alves, Cecília Pescatore, \& Cobra, Cristiane Moreira. (2013). Políticas Públicas de Educação no Brasil: possibilidades de emancipação?. Revista Gestão \& Políticas Públicas, 3(1), 132-151. Acessado em 24 de março de 2020, de: https://www.revistas.usp.br/rgpp/article/view/97890

Arroyo, Miguel G. (2012). Corpos precarizados que interrogam nossa prática profissional. Em Miguel Arroyo González., \& Mauricio Roberto. (org). Corpo-infância: exercícios tensos de ser criança: por outras pedagogias dos corpos. Petrópolis: Vozes.

Barboza, R., Pirotta, Katia Cibelle Machado., \& Pupo, Ligia. R. (2017). Educação preventiva e promoção da saúde na escola: desafios para orientação sexual em São Paulo. Revista Gestão \& Políticas Públicas, 7(1), 106-125. Acessado em 19 de maio de 2019, de: https://doi.org/10.11606/rg\&pp.v7i1.148881

Batista, Neiza., Atem, Lou M., Gemelgo, Felipe., Gonçalves, Lucila., Nolasco, Ligia., \& Rego, Renato. (2019). Escola Sem Partido e Ideologia de Gênero: reflexões sobre a educação e a luta pela construção de uma sociedade justa. Revista Gestão \& Políticas Públicas, 9(1), 162-178. Acessado em 24 de março de 2020, de: https://doi.org/10.11606/rgpp.v9i1.147234

Freire, Paulo. (1986). Educação como prática da liberdade. Editora Paz e Terra. Rio de Janeiro.

Freire, Paulo. (1997). Pedagogia da Autonomia - Saberes necessários à prática educativa. São Paulo: Paz e Terra (Coleção Leitura).

López, Nestor. (2008). A escola e o bairro: reflexões sobre o caráter territorial dos processos educacionais nas cidades. Em Luiz Ribeiro., \& Rubem Kaztman. (Orgs.). A cidade contra a escola. (pp. 327-345). Rio de Janeiro: Letra Capital, FAPERJ; Montevidéu: IPPES.

Pennac, Daniel. (1993). Como um romance. Rio de Janeiro: Rocco.

Santos, Gislene Aparecida dos. (2020). Multiculturalismo e Direitos: uma abordagem conceitual. Revista Gestão \& Políticas Públicas, 10(1), 11-31. Acessado em 24 de Agosto de 2020, de: https://doi.org/10.11606/rgpp.v10i1.183509

São Paulo. (2020a). Currículo da Cidade: Ensino Médio. Parte 1. São Paulo: Secretaria Municipal de Educação. COPED/DIEFEM/NTC. (Versão preliminar).

São Paulo. (2020b). Currículo da Cidade: Ensino Médio - Parte 2: Área de Linguagens e suas Tecnologias. São Paulo: Secretaria Municipal de Educação. COPED/DIEFEM/NTC. (Versão preliminar).

Silva, Alessandro Soares da. (2007). Direitos Humanos e Lugares Minoritários: um convite ao pensar sobre os processos de exclusão na escola. Em: Ministério da Educação. Programa Ética e Cidadania: construindo valores na escola e na sociedade. Acessado em 19 de maio de 2019, de: http://portal.mec.gov.br/seb/arquivos/pdf/Etica/11_soares.pdf

Silva, Alessandro Soares da. (2012). Psicologia Política, Movimentos Sociais e Políticas Públicas. Tese (Livre Docência). Universidade de São Paulo, São Paulo, SP, Brasil.

Silva, Alessandro Soares da., \& Ansara, Soraia. (2014). Escola e Comunidade: o difícil Jogo da participação. Em Denise D'Aurea-Tardeli \& Fraullein Vidigal de Paula. Formadores da Criança e do Jovem-Interfaces da Comunidade Escolar. São Paulo: Cengage Learning.

Soares, Carmem e cols. (1992). Metodologia de ensino da Educação Física. Cortez: São Paulo.

Vaz, Antônio Carlos. (2019). Os Direitos Humanos e as Mulheres: a escola pode civilizar?. Revista Gestão \& Políticas Públicas, 9(2), 198-216. https://doi.org/10.11606/rgpp.v9i2.176435

Recebido em 22/04/2020.

Revisado em 09/08/20. Aceito 28/10/2020. 